\title{
THE FUNDAMENTAL THEOREM OF ALGEBRA BEFORE CARL FRIEDRICH GAUSS
}

\author{
JosieP PLA I CARRIERA
}

\begin{abstract}
This is a paper about the first attempts of the demonstration of the fundamertal theorem of algebra.

Before, we antyze the tie betwen complex numbers and the mumber of roots of an equation of $n$-th degree.

In second priragraph we see the relation between the integration and fundamental theorern.

Finally, we observe the linear differential explation with constant: coeflicients and the Euler's position about the fundamental theorem and then we consider the d'A lembert's, Euler's and Laplace's dernonstrations.

It is a synthesis paper dedicated to Perc Menal a collegue and a friend.
\end{abstract}

Fis quas dormo gue hi veig clar

Josep Vicerıs FOIX

En la calle mayor de los que han inuerto, ol deber de vivir irć a gritar

Enrique BADOSA

To be or not to be.

That is the question.

William SHAKESPEARE

\section{Introduction: The Complex Numbers}

In the year 1545 Gerolamo Cardano wrote Ars Magna ${ }^{1}$. In this book Cardano offers us a process for solving cubic equations, learned from

\footnotetext{
'There are many intcresting papers on complex umbers. See, for example, Jones, P. S. [43]; Molas, C.-Pérez, J. [57] and Remmert, R. [67]. Morcover, in this paper; our interest on complex numbers is limiled only in their connexion witl algebre and particulary with the Fotndamental Theoren of Algebra.
} 
Niccolò Tartaglia ${ }^{2}$. In his book it appears for the first time an special quadratic equation:

If some one says you, divide 10 into two parts, one of which multiplied into the other shall produce 30 or 40 , it is evident this case or efuation is impossible ${ }^{3}$.

Cardano says then

Putting aside the menlal tortures involved, multiply $5+\sqrt{-15}$ by $5-\sqrt{-15}$, making $25-(-15)$, which is +15 . Hence this product is $40 \ldots$ This is truly sophisticated ... ${ }^{4}$.

But, as Remmert remembers us, "it is not clear whether Cardano was led to complex numbers through cubic or quadratic equations" 5 . The sense of these words is the following: while quadratic equations

$$
x^{2}+b=a x, \text { with } \Delta=\frac{1}{4} a^{2}-b<0,
$$

have no real roots [and they are therefore impossible equations], cubic equations

$$
x^{3}=p x+q: \text { with } \Delta=\left(\frac{q}{2}\right)^{2}-\left(\frac{p}{3}\right)^{3}<0,
$$

have real roots which are given as sums of imaginary cubic roots ${ }^{6}$. This question was further developed by Rafael Bombelli in his L'Algebra, published in Bologna in 1572. Bombelli worked out the formal algebra of

$\overline{{ }^{2} \text { Cardano's rule for cubic equation } x^{3}}=p x+\varphi$ is

$$
x=\sqrt[3]{\frac{q}{2}+\sqrt{\Delta}}+\sqrt[3]{\frac{q}{2}-\sqrt{\Delta}}, \text { where } \Delta=\left(\frac{q}{2}\right)^{2}-\left(\frac{p}{3}\right)^{3} .
$$

The listory of the process for solving cubic equations is now perfectly known. See, for example, Burton, D. M. [12, 302-312]; Stillwell, J. [76, 59-62]; Vera, F. [80, $47 \cdot 59]$ and van der Waerden, B. L. [85, 54-55].

See also Tartaglia, N. [78,69 and 120].

${ }^{3}$ Cardano, G. [16, Ch. 37]. See also Struik, D. J. [77, 67].

The equation $x^{2}-10 x=40$ for 30 ] has the solutions $5 \pm \sqrt{-15}$ |or $5 \pm \sqrt{-5}$ and boll, solutions are formally corrects, but in this time they have not any sense.

${ }^{4}$ Cardano, G. [16, Ch. 37]. See also Strutik, D. J. [77, 69 and footnote 7!.

The name imaginary is introduced by René Descartes, as we will sce soon. But it is debt, perhaps, to following Cardnno's words: "... you will nevertheless imnagine $\sqrt{-15}$ to be the difference between ..." completing, in that case, the square.

It is interesting to observe that: Cardano accompanied his result over this kind of quadratic couation with the comment: "the result in that case is as subtle as it: is useless" [see Cardano, G. [16, Ch, 37, ralc II] and also Struik, D, J, [77, 69]].

${ }^{5}$ Remmert, R. [67, 57].

${ }^{6}$ We can see van der Waterden, B. L. $[84,194]$ : It is not possible solve, by real radicals, an irreductible cubic equation ovor $Q$ whose three roots are all real [casts irreductibilis, following Caudrun]. 
complex numbers. He introduced (in actual notation) the complex mint $^{7}$ $i$ and eiglit fundamental rules of computation ${ }^{8}$ :

$$
\begin{aligned}
& (+1) \cdot i=+i ;(+1) \cdot(-i)=-i ;(+i) \cdot(+i)=-1 ;(+i) \cdot(-i)=+1 \\
& (-1) \cdot i=-i ;(-1) \cdot(-i)=+i ;(-i) \cdot(+i)=+1 ;(-i) \cdot(-i)=-1
\end{aligned}
$$

His principal aim consisted to reduce expressions as $\sqrt[3]{a+b i}$ to the form $a+d i^{6}$, because then it should be possible to use formally the Cardano's expression by solving the casus inreductibilis $x^{3}=15 x+4$. Bombelli obtains, according the Cardano's expression,

$$
x=\sqrt[3]{2+11 i}+\sqrt[3]{2-11} i .
$$

Hence $z=(2+i)+(2-i)=4$.

François Viète wrole in 1591 a higher level paper', which relates algebra to trigonometry ${ }^{10}$. In this paper ${ }^{1.1}$ Viete offers us his solution of the cubic equation by circular fonctions, which shows that solving the cubic is equivalent to trisecting an arbitrary angle ${ }^{22}$. He starts (in modern nolation) from the identity

$$
\cos 3 \theta=4 \cos ^{3} \theta-3 \cos \theta
$$

[or $z^{3}-\frac{3}{4} z-\frac{1}{4} \cos 3 \theta=0$, where $z=\cos \theta$ ]. Suppose now that the cuthic: to be solved is given by

$$
x^{3}-p x=q \quad[p, q>0] .
$$

\footnotetext{
${ }^{7} \mathrm{It}$ is perhaps interesting to remember that the symbol i for indicate amaginaty atrit is debt to Euler; "It the following I shall denote the cxpression $\sqrt{-1}$ by the letter $i$ so that is $=-1$ " [Euler, I. [25. 130]]. See Kline, M. [44, 4l0]: "] h1 his carlier work Euicr used $i$ (the first letter of infiritus) for an infinitoly large quantity. After 1777 lic used $;$, for $\sqrt{-1}$ ".

${ }^{8}$ Really, Bombelly introduced piri di meno [for $-i$ ] and meno di meno [for $\left.-i\right]$ and milos of calculation such as meno di meno vía treno di meno fa meno

which matus $(-i) \cdot(-i)=-1$.
}

Sco Bombelli, R. [9, 169] or Bertolotti reprist, 133.

${ }^{9}$ Bombelli did not through too mucl, on the nature of complex unmbers, but he knows: for example, that

$$
(2 \pm i)^{3}=2 \pm 11 i
$$

so thint

$$
\sqrt[3]{2+11 i}=2 \pm i
$$

See Fombelli, R. '9, 110 ! or Bertolotti reprint, 140-141.

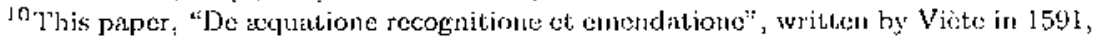
was not published uthlil $[615$ by his Scottish friend Alexander Anderson.

"Sce Viète, F. [81, Ch. VI, Th. 3].

${ }^{12}$ Sec Hollingsctale, S. $[41,122-123]$. 
If we introduce an arbitrary constant $\lambda$, setting $x=\lambda z$, then

$$
z^{3}-\frac{p}{\lambda^{2}} z-\frac{q}{\lambda^{3}}=0
$$

We can now match coefficients in the two forms

$$
\frac{p}{\lambda^{2}}=\frac{3}{4} \text { and } \quad \frac{q}{\lambda^{3}}=\frac{1}{4} \cos 3 \theta, \text { so that } \quad \lambda=\sqrt{\frac{4 p}{3}}
$$

With this value of $\lambda$, we can select a value of $\theta$ so that

$$
\cos 3 \theta=\frac{4 q}{\lambda^{3}}=\frac{q / 2}{\sqrt{(p / 3)^{3}}}
$$

In the casus irreductibilis, we have

$$
\Delta=\left(\frac{q}{2}\right)^{2}-\left(\frac{p}{3}\right)^{3}<0 \text { and then }\left|\frac{q / 2}{\sqrt{(p / 3)^{3}}}\right|<1
$$

and thus the condition for three real roots ensures us that $|\cos 3 \theta|<1$, which is essential ${ }^{13}$.

In 1637 René Descartes wrote La Géométrie ${ }^{14}$. This appendix waS his only mathematical work; but a what work! It contains the birth of analytic geometry ${ }^{15}$. In Book III of his La Géométrie Descartes gives a brief summary of that was known about equations ${ }^{16}$. Between his

${ }^{13}$ Then he proves the cquivalcnce: we have $\cos 3 \theta=\mu$, where $\mu=\frac{q / 2}{\sqrt{(p / 3)^{3}}}$. Given $\mu$, we can construct a triangic wilh angle $3 \theta=\cos ^{-1}$ ft. Trisection of this angle gives us the solution $z=\cos \theta$ of the equation. Conversely, the problem of trisecting an angle witls cosine $\mu$ is equivalerst to solve the cubic equation $4 z^{3}-3 z=\mu$.

${ }^{14}$ It is, as it is well known, the third appendix of his famons Discouts de la methode pour bien condtizie sa raison el chercher la verité dans les sciences. The other appendices are La Dioptrique and Les Météors. For a comment we can see Bos, H. J. M. [10], Millaud, G. [56, 124-175], Pla, J. [63], or Scott; J. F. [77, 84-157].

${ }^{15}$ The analytic geometry was independently discovered by Pierre Fermat, a French amateur mathemalician, in his "Ad locos planos et solidos isagoge" [32].

16 "John Wallis in his Atgebra [86] declared that there was little in Descartes which was to to be found in the Artis Analyticas Praxis [39] of Harriot" jsec Scott: J. F. [77, $138]$ and Wallis, J. $[87,126]]$. But, says Scott [Scott, J. [71, 139]], "this statement is far from true". 
algebraic assertions ${ }^{17}$, we are interested in the following:

in every equation there are as many distint roots as is the number of dimensions of the unknoun quantities ${ }^{18}$.

This is an important, approach to Fundamental Theorem of Algebra, but it is not the first and perlaps never the more explicit.

The first writer to assert that "every such equation of the nth degree las $n$ roots and no more" secris to have been Peter Roth ${ }^{19}$. The law was next set forth by a more prominent algebraist, Albert Girard, in 1629:

Every algcbraic equation admits as many solutions the the denomination of the highest quantity indicates...20

Girard gives no proof or any indication of one. He merely explains his proposition by sone examples, including that of the equation $x^{4}-4 x+$ $3=0$ whose solutions are $1,1,-1+i \sqrt{2},-1-i \sqrt{2}^{21}$.

17The other important assertions in Book III of LA Géométrie arc:

- A polynomial $P(x)$ which vanishes at $c$ is always divisible by tho factor $x-c$ and then

$$
P(x)=(x-c) \cdot Q(x), \text { where } \operatorname{deg}(Q(x))=\operatorname{deg}(P(x))-1
$$

TThis theorem was probably already known by Thomas Harriot, following Remmert. R. [68, 99 foolnote 2'.]

- Descartes' mile of signs: we carl determinate from this also the mumber of true and false roots that any equation can havc, as follows: Every equation can have as manty trute roots as it contains changes of signs, from + to - or from - lo + ; and as mamy false roots as the number of limes two + signs or two - signs are found in succession. [This law was apperently known by Cardino [Cantor, N. I[15, II, 539], but; is satisfactory statement is possibly due to Harriot [1]arrio1, $[39,38,268]]$. See also Smith, E. D. [73, 1], 471 i.] [On limitations or mistakes in Descartes: rule sce, for example, Scott, J. F. $[71,140]$.]

This rule was formulated in a more precisc manner by Isanc Newton in his Arithmetica Universulis, composed botween 1673 and 168:3, perhaps for Newton's lectures at Canbridge, but first published in 1707. Newton's rule counts morcover complex roots.

'This Newton's work contains also the formulas, uslally known as Newton's idertities, for sums of tic power of the roots of polynomial equations.

${ }^{18}$ Jescartes, R. [19, 372]. English trans]ation in Smith, D.E.-Latham, M. [75, 159]. 19 Poter Roth, who nume also appoars as Rothc, was a Nürnberg Rechenmeister, died at: Nürnberg in 16 17. He wrote, in 1600, his Arithmetica philosophica, where we can find the quoted slatement.

${ }^{20}$ See Girard, A. [38] in Viète and alii $[83,139]$ and in Struik, D. J. [77, 85]. Sce also Troplke, J. [79, III(2), 95] for further cletails.

21 There are opposed opinions about the real content in these formulations. Whilst for Smith [Suth, D. E. $[73,11,471]]$ "this law was more clcarly expressed by Descartes 
Iater another mathematician, named Rahn [or Rohnius], also gave a clear statement of the law in his Teutschen Algebra [66].

The question about these formulations of the Theorem is the following: these algebraists accepted real and complex numbers and only them as solutions of equations? The answer is not easy nor clear. Girard accepts the "impossible solutions" with these words

Someone could also ask what these impossible solutions are. I would answer that they ore good for three things: for the certaintly of the general rule, for being sure that there are no other solutions, and for its utility ${ }^{22}$.

Descartes, by his side, realized the fact that an equation of the nth degree has exactly $n$ roots ${ }^{23}$. But, for Descartes, the imaginary roots do never correspond any real quantity ${ }^{24}$.

[19], who not only stated the law but distinguished between real and imaginary roots and between positive and negative real roots in making the total number", for Remmert [Remmert, R. [68, 100]], contrarily: "Descartes takes a rather vague position on the thesis put forward by Girard".

${ }^{22}$ Girard, A. [38] in Viète and alii $[83,141]$. In other side [Viète and alii [83, 142]] he say's: "Thus we can give three names to the other solutions, seeing that there are some which are greater than nothing, other less than nothing, and other enveloped, as those which have $\sqrt{-}$, like $\sqrt{-3}$ or other similar numbers."

Remmert, R. [68, 99], goes further. He says: "F[c thus leaves open the possibility of solutions which are not complex". Remmert thinks that; in his ambiguity, Girard leaves an open door to the solutions more complicated than the complex. The problem consists to know the exact sense of the Girard's words "impossible solutions" because; for him, "there are no other solutions". [About this question sec also Gilain, C. [37, $93 \cdot 95]$.

${ }^{23}$ This assert is debt to the Descartes' text. [see Descartes, R. $[19,380]$. English translation in Smith, D.E.-Latham, M. [75, 175]]:

Neither the true ror false rools are real; sometimes they are imaginary; that is, while we can always conceive of as many roots for each equation as I have atready assigned, yet there is not always a definite quantily corresponding to each root so conceived of. Thus, while we may conceive of the equation

$$
x^{3}-6 x^{2}+13 x-10=0
$$

as having threc roots, yet therc is only one real root, 2, while the other two, however we may increase, diminish, or multiply them in accordance with the rules just laid doun, remains always imaginary.

In this text there is a rather interesting classification signifying that we may have positive and negative roots that are imaginary

It $5 \mathrm{ccms}$ that for Descartes the roots are always real or inaginary and no other kind of root is possible. [About with this oppinion, see Gilait, C. [37, 95-97].]

The use of word imaginary in his actual sense begin here [sec Smith, D.E.-Latham, M. [75, 175, footmote 207]\}.

${ }^{24}$ Descarties confess that one is quite unable to visualize imaginary quantities [sce 
This impossibility or difficulty for visualizing imaginary quantities was perhays the reason which carried the English mathematician John Wallis to give a geometrical interpretation in his Treatise of Algebra of $1685^{25}$.

He says: "The Gometrical Elfection, therefore answering to this Equation

$$
a \cdot a \mp b \cdot a+c=0
$$

may be this" 26 .

Smith: 10.15.-Latham, M. [75, 187]]. As snys Remumert, R. [67, 58], "Newhon regarded complex quantities as indication of the insolubility problem". In the Newton's own words: "But it is just that the Roots of Equation should be impossible, lest they should exhibit the canes of Froblems that are impossible ins if they were possible" [Newton, 1. [59] 2nd ed., 19!3].

25 This representation is quoted in Smith, D. E. [74, 46-54]. Sec also Stillwell, J. C. [76, 191-192]]. In a letter to Collins, May 6, 1673, Wallis suggests a construction a little diftorcut; from any of the constructions found in his Algebraz [sec Cajori, $F$. [13]]. Wo shafl see this alternetive construction licre:

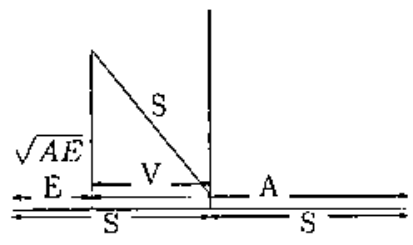

Jigure lis

"r'lis imaginable root in a cuactratic equation I kave bad thoughes long sinec of designing geometrically, and have had sevoral projects the that purpose. One of them was this:

Supposirig a quadratic equitition

$$
A^{2}-2 S A+A E=0
$$

If $S\left[=\frac{A+E}{2}\right]$ be bigger than $\sqrt{A E}$ [that is $\left.S^{2}>A E\right]$, the rook alde $S \div \sqrt{S^{2}-A E}=$ $\left\{\begin{array}{l}A \\ E\end{array}\right.$, putting $\ldots, S=\frac{1}{2} Z$ and $\ldots V=\frac{1}{2} X$, where $V\left[=\sqrt{S^{2}-A E}\right]$ adkled to and lakes from $S$, yiclds $S+V=A, S \quad V=E$, that is, fllte toots, are] $S \pm \sqrt{V^{/ 2}}$ [sec ligure la\}.

But if $A E$ be bigger thin $S^{2}$, the roots are $S \pm \sqrt{S^{2}-A E}=\left[S \pm \sqrt{V^{2}}\right]$, where

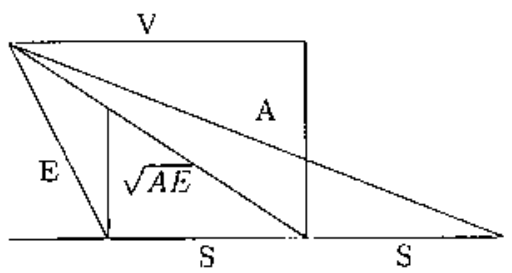

Figure lb

$\sqrt{A E}$, which was the sinc, now become the sectult, and $V$, that was the cosine, is now the tangent [sec figure $] \mathrm{b}$ ]. For $S^{2}-A E=V^{2}$, the difference of the plane $S^{2}$ and $A E$, the greaticr is to be expressed by the hypotinuse, and the lesser by the perpendicular."

${ }^{26}$ Wallis, J. [87] in Suith, D. E. [74, 52]. Wallis calls the independent term eae. It is the product of two roots a ind $e$ of the cquation $a \cdot a \mp b \cdot a+a e=0$.

Before this, Wallis offer's as the following calculation for solving

$$
a \cdot a \cdots 2 a \sqrt{175}+256=0 .
$$


On $A C \alpha=b$ bisected in $C$, erect a Perpendicular $C P=\sqrt{c}$. And taking $P B=\frac{1}{2} b$ make a Rectangular Triangle [figure 3a].

If $P C=\sqrt{c}<\frac{1}{2} b=P B$, then the solutions are Real and are precisely $A B$ and $B \alpha$.

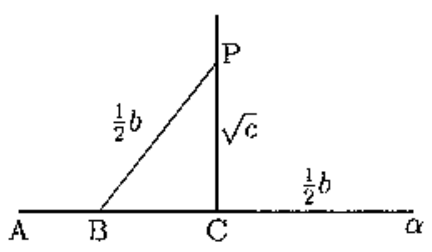

Figure 3a

[In this case $A B=\frac{1}{2} b-\sqrt{\frac{1}{4} b^{2}-c}$ and $\alpha B=\frac{1}{2} b+\sqrt{\frac{1}{4} b^{2}-c}$ [see Smith, D. E. $[74,53]]$.]

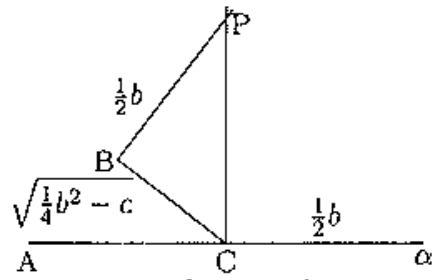

Figure 3b
But if $P C>P B$, "the above construction fails" and "the Right Angle will be at $B^{\prime \prime}$. Then the solutions are Imaginary and are $A B$ and $\alpha B$ [see figure $3 \mathrm{~b}$ ]. [Now $A B=\frac{1}{2} b-i \sqrt{c-\frac{1}{4} b^{2}}, \alpha B=$

$\frac{1}{2} b+i \sqrt{c-\frac{1}{4} b^{2}}$. Wallis uses the later $B C$ to obtain the imaginary part of the solution.]

This geometrically representation was not accepted by the mathematicians $^{27}$ and would be still necessary to wait a hundred years to obtaining

The solutions are $a=\sqrt{175}+\sqrt{-81}$ and $e=\sqrt{175}-\sqrt{-81}$. The geometrical representation is [following Wallis, J. [87] in Sinith, D. E. [74, 50-51]]:

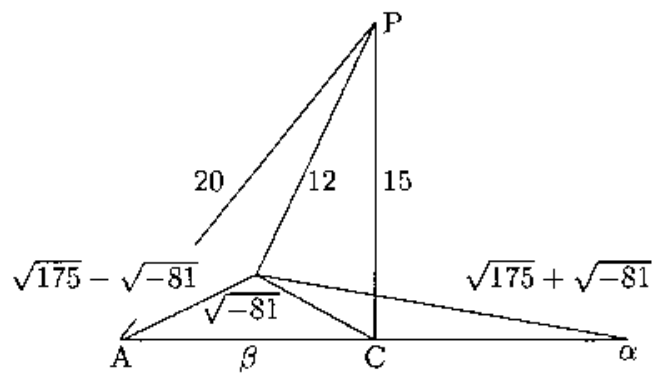

Figure 2

${ }^{27}$ In Stillweil, J. $[\mathbf{7 6}, 192]$, we can see the Wallis' figures and the modern 
the correct and acceptable representation ${ }^{28}$. We shicll not comment this work.

\section{The technique of integration and complex quantities}

The eighteenth century use of the integral concept was limited. Newton represented the transcendental functions as series and integrated these functions term by term ${ }^{29}$. Gottfried Wilhelm Leibniz and Johann Bernoulli treated the integral as the inverse of the differential ${ }^{30}$.

In this context the decomposition of rational fractions [or functions] into partial [or simple] fractions made possiłle a decisive step in integra] calculus ${ }^{31}$.

The problem was calculate the integral

$$
\int \frac{P}{Q} d x
$$

where $P$ and $Q$ are polynomials and $\operatorname{deg}(P)<\operatorname{cog} Q$ and, for getting it, Gottfried Wilhelm Leibniz and Joham Bernoulli, together other nathematicians of his tiure, saw the necessity to express every real polynomial as product of real factors of first and second clegree ${ }^{32}$. This fact shows us that they had very much confidenes in the Fundamental Theorem of Algebra ${ }^{33}$.

represcritalion.

28 'The sat isfactory geometrically representation of conplex quantities was carried by the Norwegian mathematician Caspar Wessel in 1797 and independently by the Swiss Jcan Robert Argand in 1806 . 'This listi work, despite ils cunsiderable merit, remained unnoticed until a French translation apperead in 1897.

${ }^{29}$ Sec Plak, J. [64, 9-20].

${ }^{30}$ See Kline, M. [44, 406]: "If $d y=f^{\prime}(x) \cdot d x$, then $y=f(x)$. That: is, a Newtonian antiderivative was chosert as the integral, but differentials wcre used in place of Nowton's derivatives".

31' l'he existence of an istegral was never questioned.

${ }^{32}$ 'The Arithmetica Universatis of Isate Newton contains, as wo have said before, the substance of Newton's lectures from 1673 to 1683 at Carnbridge. In it are found many importath resilts in equations theory, sucl as the fact that the imaginary roots of a real polynomial "must occur in conjugate pairs". "This lact is a very important result and it was naturally accepted by the mathemalicians of the end of severtecenth century. But, [ollowing I,cibniz, this fact presents difficulties, ats we shall see next.

${ }^{33}$ See Leibuiz, G. W. [49], :51] and Bernoulli, Jh. |6].

I'he chince did that. in 1702 , July 10, Joham Pernoulli, Lhinking to emunciate hin a now result, wrote to Leibuiz that had found the integral of differential quantities $\frac{p}{q} d x$, where $p$ and $q$ are polynomials. But Lecibuiz responded: "No only I have altready the solution of this problem, but morcover l have it from the first years in which I practiced the higlier geonetry. In this result I have seen an essential component of 
The exact Bernoulli's text is:

Let the differential be $p d x: q$ which $p$ and $q$ express rational quantities composed arbitrarily of a single variable $x$ and constants; one seeks the integral or the algebraic sum or the means of reducing it to the quadrature of the hyperbola or the circle, the one or the other always being possible ${ }^{34}$.

And next he says that $\frac{d x}{x \pm a}$ is the differential of logarithm of $x \pm a$. Therefore

$$
\begin{aligned}
\int \frac{a d x}{x+f}+\int \frac{b d x}{x+g}+ & \int \frac{c d x}{x+h}+\cdots= \\
& =\log \left\{(x+f)^{a} \cdot(x+g)^{b} \cdot(x+h)^{c} \cdots\right\} .
\end{aligned}
$$

But the remarkable question is that "complex numbers made their entry to the theory of circular functions". The process is the following: he observes that "one transforms the differential $\frac{a d z}{b^{2}-z^{2}}$ into a logarithmic differential $\frac{a d t}{2 b t}$ and reciprocally" 35 and, as a corollary, "one transforms the differential $\frac{a d z}{b^{2}+z^{2}}$ in the same way into $-\frac{a d t}{2 b i t}$, an imaginary logarithmic differential and reciprocally" 36 . But then he observes that $\frac{a d z}{b^{2}+z^{2}}$ can

my science of the infinite, and hence of the integral analysis ..." [Leibniz, G. W. [49, 703]].

"When, in 1746, Jean le Rond d'Alembert drew people's attention to the need to prove that theorem, he was to cite Bernoullis' paper as a particulary important use of it" [see Fauvel, J.-Gray, J. [31, 435]],

${ }^{34}$ Benuulli, Jh. [6] in Opera Omnia, I, 393 or Fauvel, J.-Gray, J. [31, 439].

${ }^{35}$ He uses the change of variable $z=b \frac{t-1}{t+1}$ and observes that $\frac{a d z}{b^{2}-z^{2}}$ goes over into $\frac{a d t}{2 b t}$ [see Fauvel, J.-Gray, J. [31, 438]]. How does Johann Bernoulli obtain this result? It is clear that Johann Bernoulli knows the integral of rational functions as $\frac{a}{b^{2}-z^{2}}$, because he knows the decomposition of the rational functions into simple functions:

$$
\frac{a}{b^{2}-z^{2}}=\frac{a}{2 b} \cdot \frac{1}{b-z}+\frac{a}{2 b} \cdot \frac{1}{b+z} \text {. }
$$

And then he applies his technique and obtains

$$
\int \frac{a d z}{b^{2}-z^{2}}=\frac{a}{2 b} \cdot \log \frac{b+z}{b-z}=\frac{a}{2 b} \cdot \int \frac{d t}{t}, \text { where } t=\frac{b+z}{b-z}
$$

and then $z=b \cdot \frac{t-1}{t+1}$.

${ }^{36}$ Similarily, the differential $\frac{a d z}{b^{2}+z^{2}}$ goes over, by the substitution $z=b i \frac{t-1}{t+1}$, into $-\frac{a d t}{2 b i t}$ [see Fauvel, J.-Gray, J. [31, 438]].

Remember that, in 1699, Jakob Bernoulli had evaluated [see Bernoulli, Jk. [1699], 868-870] the integral of $\frac{a^{2} d x}{a^{2}-x^{2}}$, using the change of variable $x=\frac{a}{2} \cdot \frac{b^{2}-t^{2}}{b^{2}+t^{2}}$; this converts the integrand $\frac{a^{2} d x}{a^{2}-x^{2}}$ into $\frac{d t}{2 a t}$. [See Kline, M. [44, 407].] 
be transformed also [using now $z=\sqrt{\frac{1}{t}-b^{2}}$ ] into the differential of "a sector or circular arc $-\frac{n d t}{2 \sqrt{t-t^{2} t^{2}}}$ and reciprocally". Finally he observes that the integral of

$$
\frac{a d z}{b^{2}+z^{2}}
$$

depends on the quadrature of the circle, and moreover

$$
\frac{a d z}{b^{2}+z^{2}}=\frac{1}{2 b} \cdot \frac{a d z}{b+i z}+\frac{1}{2 b} \cdot \frac{a d z}{b-i z}
$$

which are two differentials of imaginary logarithms: one sees that imaginary logarithms can be taken for real circular sectors because the compensation uhich imaginary quantities makes on being added together of destroying themselves in such a way that their sums is always real ${ }^{37}$.

We have observed there the introduction of imaginary logarithmic differential into the integration of rational functions ${ }^{38}$.

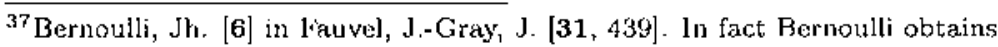

$$
\tan ^{-1} z=\frac{1}{2 i} \cdot \log \frac{i-z}{i+z} \text {. }
$$

In this sense it is interesting to note that, several years later, in 1712 , Johann Bernoulli carried ont the integration to obtain an algebraic relation between $\tan n \theta$ and $\tan \theta$. His argument is as follows. Giver

$$
y=\tan n \theta, \quad x=\tan \theta,
$$

we have

$$
n \theta=\tan ^{-1} y=n \cdot \tan ^{-1} x
$$

hence, taking differentials,

$$
n d \theta=\frac{d y}{1+y^{2}}=n \cdot \frac{d x}{1+x^{2}}
$$

and then

$$
\left[\frac{1}{y+i}-\frac{1}{y-i}\right] \cdot d y=n\left[\frac{1}{x+i}-\frac{1}{x-i}\right] \cdot d x .
$$

Integration gives

$$
\log \frac{y+i}{y-i}=\log \left[\frac{x+i}{x-i}\right]^{n}
$$

and whence

$$
(x-i)^{n} \cdot(y+i)=(x+i)^{n} \cdot(y-i) .
$$

${ }^{38}$ We do not explain the history of imaginary logarithm. But there are many papers on complex loguril.hms as; for example, Cajori, F. [14], Klinc, M. [44, 407-408]; Naux, I. $[58]$ and Stij]wol], J. $[76,220-222\}$. 
But this siluation is not easier than it seems. In his presentation about the integral of rational functions, Leibniz shows us a difficulty, a limitation or merely a question. It is always possible decompose a real polynomial into a product of real lineal factors or real quadratic factors? ${ }^{39}$ or, every polynomial has always a real and complex root and, with every complex root, has also the conjugate complex root? Although always Leibniz is clear and rotund when he says

As soon as I had found my Arithmetic Quadrature, reducing the quadrature of circle into a rational quadrature and observing that the sum

$$
\int \frac{d x}{1+x^{2}}
$$

depends of the quadrature of the circle, I immediately observed that a time reduced to the summation of a rational expression, all quadrature carl be converted in many kinds of summation of the more simple. And I will shou, by a decomposition proceeding of a new genus because it must be in this manner. This proceeding consists to convert a product of factors into a sum; this is, to transform a fraction with a denominator of higher degree, equal. to product of roots, into a sum of fractions with simple denoninators, 40

when he must integrate $\int \frac{d x}{x^{4}+n^{4}}$ he finds a problem. It is possible obtain $\frac{1}{x^{4}+a^{4}}$ to multiply $\frac{1}{x^{2}+i \alpha^{2}}$ by $\frac{1}{x^{2}-i a^{2}}$, but they are not real. And it is not possible to obtain a real decomposition, because

${ }^{39}$ This asserl is absolutely clear in Newton, I. [59], as we have seen in the footnote 32 .

${ }^{40}$ Lejbniz, G. W. $[50,351-352]$.

In this work Leibniz obtains naturally the integration of rational functions, as for example

$$
\int \frac{d x}{x^{2}-1}=\frac{1}{2} \cdot \int \frac{d x}{x-1}-\frac{1}{2} \cdot \int \frac{d x}{x+1}
$$

although " $\int \frac{d y}{y}$ is the quadrature of the hyperbola".

Next year Leibriz studies the case in which the roots are not simple and therofore the sum is transformated into the sutn of [ractions with multiple denominators [see Lcibniz, G. W. [51]]. 


$$
x^{4}+a^{4}=[x+a \sqrt{i}] \cdot[x-a \sqrt{i}] \cdot[x+a \sqrt{-i}] \cdot[x-a \sqrt{-i}]^{41}
$$

and therefore it is not possible to reducc $\int \frac{d x}{x^{4}+4 t^{4}}$ to the quadrature of the circle nor to the quadrature of the hyperbola. It would be necessary to introduce the quadrature of $\int \frac{d t x}{x^{4}+a^{4}}$ as in new function ${ }^{42}$.

There is neither hesitation abont the importance which Leibniz granted the complex numbers and his contributions, "when they werc almost forgotten", were remarkablet3. Between these it is interesting to observe that he oblained an inaginaty decomposition of a positive real number which surprised his contenporaries and enriched the theory of inaginaries:

$$
\sqrt{6}=\sqrt{1+\sqrt{-3}}+\sqrt{1-\sqrt{-3}} 4
$$

${ }^{41}$ Leibuiz does not observe that.

$$
x^{4}+a^{4}=\left[x^{2}+a \sqrt{2} x+a^{2}\right] \cdot\left[x^{2}-a \sqrt{2} x+a^{2}\right] .
$$

The possible mistake is klobt to have begun by the complen conjugate decomposition

$$
x^{4}+a^{4}=\left[x^{2}+i a^{2}\right] \cdot\left[x^{2}-i a^{2}\right] .
$$

${ }^{42}$ We have alrcady introducol the guadrature of the hyperlola $\int \frac{\text { sfar }}{x+a}$ ared the quadraqure of circle $\int \frac{d x}{x^{2}+a^{2}}$. Then, says Leibniz, "I wait that we will bo able to follow this progression and wc will found the problems related with $\int \frac{d x}{x^{4}+\alpha^{4}} ; \int \frac{d x}{x^{8}+a^{8}}, \ldots$ " [sec Leibniz, G. W. $[50,360] \mid$.

${ }^{43}$ Moreover, for Lcibniz, complex numbers are the natural consecucnce of have accepted real numbers: "Fron the irrationals are born the impossible or imaginary guantities whose nature is very strange but whose uscfulness is not to be despised" [sec Leibniz, G, W. [50, 5i]].

${ }^{44} \mathrm{Sec}$ a letter from Leibuiz to lhygens, writen in 1674 or 1675 [Gerhardt, C. I. [36, 5633] and sce also Hofmam, J.E. ,1972], 147 and McClonon, R. B. [55]]: "I once came upon two equations of this kind $x^{2}+y^{2}=b, x \cdot y=c$ ". He oblains then

$y=\sqrt{\frac{b}{2}+\sqrt{\frac{b^{2}}{4}-c^{2}}}$ and $x^{2}-\frac{b}{2}+\sqrt{\frac{b^{2}}{4}-c^{2}}=0 \quad$ or $\quad x=\sqrt{\frac{b}{2}-\sqrt{\frac{b^{2}}{4}-c^{2}}}$

Then

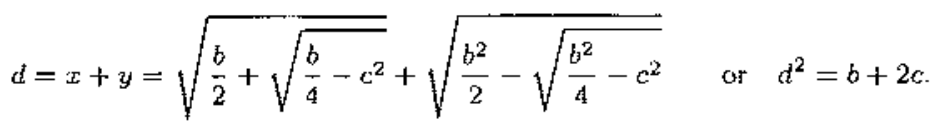


Moreover, as says Boyer, "Leibniz did not write the square roots of complex numbers in standard complex form, nor was he able to prove his conjecture that

$$
f(x+i y)+f(x-i y) \text { is real }
$$

if $f(z)$ is a real polynomial." 45

Finally in an unpublished Leibniz's paper ${ }^{46}$ appears the so-called de Moivre's formula. He does not explain how he found it, but it is comprehensible to us as

$$
2 y=\sqrt[r]{x+\sqrt{x^{2}-1}}+\sqrt[r]{x-\sqrt{x^{2}-1}}
$$

where $x=\cos \theta, y=\cos \frac{\theta}{n} 47$. But these important mathematical contributions did not enough to clarify the nature and reality of the complex numbers.

Finally

$$
\sqrt{b+2 c}=\sqrt{\frac{b}{2}+\sqrt{\frac{b}{4}-c^{2}}}+\sqrt{\frac{b^{2}}{2}-\sqrt{\frac{b^{2}}{4}-c^{2}}}
$$

If we put $b=2$ and $c=2$, there resultis $\sqrt{6}=\sqrt{1+\sqrt{-3}}+\sqrt{1-\sqrt{-3}}$.

But that what results really surprising is the use of Cardano's rule by obtaining this kind of results. Taking Atbert Girard's equation

$$
x^{3}-13 x-12=0,
$$

whose true root is 4 and the sum of roots is zcro, Lcibniz obtains

$$
4=2+\sqrt{-\frac{1}{3}}+2-\sqrt{-\frac{1}{3}}=\sqrt[3]{6+\sqrt{\frac{-1225}{27}}}+\sqrt[3]{6-\sqrt{\frac{-1225}{27}}} .
$$

By using the equation

$$
x^{3}-48 x-72=0
$$

he shows finally that

$$
-6=\sqrt[3]{36+\sqrt{-2800}}+\sqrt[3]{36-\sqrt{-2800}}
$$

Hofmann says us "the identity (*) is implicit in Euclide's book X, 47-54 [if $4 c^{2}<$ $\left.b^{2}\right)$, but "nobody noticed it at the lime".

${ }^{45}$ Boyer, C. B. $[11,444]$. This conjecture is donc by Leibniz in Gerhardt, C. I. [36, $550]$.

${ }^{46}$ I eibuiz, G. W. [49].

${ }^{47}$ See Hofmann, J.E. [1972], 145-146; Schneider, I. [72, 224-229] and Stillwell, J. 
Leibniz adventures his mistic nature, saying: "The nature, mother of the etcrnal cliversitjes, or the divine spirit, are zaelous of her variety by accepting one and only one pattern for all things. By these reasons she has invented this elegant and admirable proceeding. 'This wonder of Analysis, prodigy of the universe of ideas, a kind of hermaphrodite between existence and non-existence, which we have named imaginary roots" 48 .

This mysterious character stood during several centuries, may be until the Euler's time with the contributious of the own Euler and d'Alembert.

Kline is absolutely clear in this seuse:

Complex numbers were more of a bane to the eighteenth-century mathematicians. These nambers were practically ignored from their introduction by Cardan antil about 1700. Then complex numbers were ased to inlegrate by the methode of partial fructions, which was followed by the lengthy controversy about complex numbers and the logarithns of negative and complex numbers. Despite his correct resolution of the problem of the logarithms of complex numbers, neither Euler nor the other nathematicians were clear aboul those numbers.

Euler tried to understand what comples numbers really are, and in his "Vollständige Anleitung zur Algebra", which first appeared in Russian in 1768-69 and in Germany in 1770 and is the best algebra text of the eightecrth century, says,

Because all conceivable numbers are either greater than zero or less than 0 or equal to 0 , then it is clexur that the square roots of negative numbers cannot be included among the possible numbers [real numbers]. Consequently we must say that these are impossible numbers. And this circumstance leads us to the concept of such numbers, which by their nature are impossible, and ordinarily are called imaginary or faricied numbers, because they exist only in the imagination

Euter made mistakes with complex numbers. In this Algebra he writes $\sqrt{-1} \cdot \sqrt{-4}=\sqrt{4}=2$, because $\sqrt{a} \cdot \sqrt{b}=\sqrt{a \cdot b}$. He also gives $i^{i}=0.2078795763$, but misses other values of this quantity ${ }^{49}$.

[76, 56-57]. Morcover Leilmiz is conscious of this result and "when it appeared in De. Moives's paper in the Philosophical Transactions, 20, $1^{\circ} 240$ of May 1698 (published in 1699), Leibniz - quile modest.ly - put in his riglit:ul claim of aluthority in Acta Erodztomim (May 1700): 199-208 [Gerhatdt, C. 1. [35, V, 346-347]]" [see Hofmann, J.E. [1972]: 146, footunte 17 !.

${ }^{48} \mathrm{~J}$ eibniz, G. W. $[49,357]$.

${ }^{40} \mathrm{Kline}, \mathrm{M} .[44,594]$. 


\section{The three first attempts to prove the Fundamental Theorem of Algebra}

One possible enunciate of the Fundamental Theorem of Algebra ${ }^{50}$ is: Every polynomial $P(x)$ with real coefficients has a complex root.

Before 1799, year in what Karl Friedrich Gauss gave his first rigorous proof of Fundomental Theorem of Algebra ${ }^{51}$, three important mathematicians had already made three attempts to prove the Theorem. The first is debt to a French mathematician and philosopher, Jean le Rond d'Alembert, and was published in 1748, but elaborated in 1746. Three years later, in 1749 , Leorhard Euler gave an algebraic demonstration, very different of the d'Alembert's demonstration. This demonstration was completed by Joseph Louis Lagrange in $1772^{52}$. Several years later another French mathematician, Pierre Simon Laplace, tried to prove the Theorem. It was the year $1795^{53}$.

\footnotetext{
${ }^{50}$ There are excellent papers about the Fundanentat Theorem of Algebra. See, for example, Bashmakova, 1. [4], Dieudonné, J. et alii [20,68-71], Gilain, C. [37], Houzel, C. 142]: Petrova, S. S. [61], Remmert, R. [67] and van eler Wacrden, B.L. [1980], 94102 .

The Givains's text offers us a distintion bctween the Fundamental Theorem of Algebra - sometimes known as the d'Alembert's Theorem- and the Theorem of linear factorization - sometimes known as the Kronecker Theorem-very clever for understand posterior developments and clarify the different kinds of demonstrations [see Gilain, C. $[37,92\}]$.

But I think that, historically, this distirition is not clear. The former mathomaticians to Gauss was not conscious of that fact.

${ }^{51}$ Gauss considered the Theorem so important that he gave fotr proofs; the principles on which the first is based was discovered by Gauss in October 1797, but the proof was not published until 1799. In this proof, similar to d'Alembert's attempt of proof: he does not introduce complex numbers. He proves the Theorem in the form:
}

Every polynomial $P(x)$ with real coefficients can be factored into linear or quadratic factors.

The second and third proofs of Theorem were published in 1816. The second proof is purcly algebraic, following perhaps the Euler's intention. The forth proof is based in the same principle of the first and was published in 1849. In this proof Gauss uses already complex numbers more frecly because, he says, "they are now common knowledge". In the third proof he used, in fact, that what we today know as the Cauchy integral theorem.

A half century dedicated by Gauss to prove the Theorem.

Following these different demonstrations we can find precisely the differences noted by Gilain.

${ }^{52}$ The Euler and Lagrange attempts were published, respectively, in 1751 and 1774.

53 Pierre Simon Laplace made an attempt to prove the Theorem, quite clifferent from the Euler-Lagrange atiempt but also algebraic, in his Leçons de mathématiques donnés a l'Ecole Nomal, published in 1812. 
Really therefore was Euler the first of these three mathomaticians which asserted the true of the Theorem. So ini a letter to Nikolaus Bernoulli, Euler connuniates the factorization theorem for real polynomials, closing the question posed by Leibnizist.

54 We have already seen that "does not sem to have ocurred to leibniz that $\sqrt{i}$ could be of the form $a+b i$, because if he hat seen that

$$
\sqrt{i}=\frac{1}{2} \sqrt{2} \cdot[1+i] \quad \text { and } \quad \sqrt{-i}=\frac{1}{2} \sqrt{2} \cdot[1-i]
$$

he would have noticed that the product of the factors

$$
[X+a \sqrt{i}] \cdot[X+a \sqrt{-i}] \text { and }[X-a \sqrt{i}] \cdot[X-a \sqrt{-i}]
$$

are botlit reals and then he would lave obtained

$$
X^{4}+a^{4}=\left[X^{2}+a \sqrt{2} X+a^{2} \cdot\left[X^{2}-a \sqrt{2} X+a^{2}\right]\right.
$$

So he wuolel have avoid his noistake. It is romatkable that he should not have been led to this facturization by the simple advice for writing $X^{4}+a^{4}=\left[X^{2}+a^{2}\right]^{2}-2 a^{2} X^{2}$ " [see Remmert, R. [67, 100]].

Sec also Kline, M. [44, $597-598]$ : “. . L Libniy did not bolieve that every polynomial with real cocficients could be clecomposed into linear and quadratic factors. Euler took tle correct position. In a Ietter to Nikolaus Bernoulli of October 1, 1742, Euler affirmed without proof that a polytiomial of arditraty degree with real coefficients could be so expressed [soc Euler, L. [1.862], I, 525]. Nikolaus did not belicve the assertion to be correct and gave the exumple of

$$
x^{4}-4 x^{3}+2 x^{2}+4 x+4
$$

with the imaginary rooks $1+\sqrt{2+\sqrt{-3}}, 1-\sqrt{2+\sqrt{-3}}, 1+\sqrt{2-\sqrt{-3}}, 1-$ $\sqrt{2-\sqrt{-3}}$, which he said contradicts Euler's assertion [see Euler, L. [27, 11, 695]]". On December 15, 1712. Eujer into a letter to Goldback [see Euler, L. [27, I, 170-171]], after assert that he doubted once when lie snw this cxample, diel it doubt once soen the example, "pointed out the comples roots occtur" in conjugate pairs, so the produt of $x-[a+b i]$ and $x-[a-b i]$, wherein $a+b i$ and $a-b i$ are a conjugate pair, gives a quadratic expression with real coefficients. Euler then showed that his was true for Bermoulli's extunple. But Goldbach, too, rejected the idea that every polynomial with real cocficients can be factorcd into real factors and gave the example $x^{4}+72 x-20$ [sec the letter from Goldbach to Euler of february 5, 174:3 in Euler, L. [27, I, 193]]. Euler then showed Goldbach that the later frad inade a mistake and that he [Euler] had proved this lincoren for polynomials up to the sixth degree. Howcver, Cooldbach was not convinced, because Euler did not succeded in giving a general proof of this assertion".

"The reader interested to follow the succession of these letiers can see, for cxample, Gilain, C. [37, 106-108]. 
Next year, in a very important paper ${ }^{55}$, Euler thinks about the homogeneous $n$ th-order differential equation with constant coefficients

$$
0=A y+B \frac{d y}{d x}+C \frac{d^{2} y}{d^{2} x}+D \frac{d^{3} y}{d^{3} x}+\cdots+L \frac{d^{n} y}{d^{n} x},
$$

where $A, B, C, D, \ldots, L$ are constants. He points out that the general solution of [1] must contain $n$ arbitrary constants and the solution will be a sum of $n$ particular solutions $y_{j}$, every one multiplied by an arbitrary constant. So the general solution of $y$ has the form

$$
y=C_{1} y_{1}+C_{2} y_{2}+\cdots+C_{n} y_{n}
$$

Then he makes in [1] the substitution

$$
y=e^{\left[\int r d x\right]}, \quad \text { with } r \text { constant, }
$$

and obtains the polynomial equation in $r$,

$$
A+B r+C r^{2}+\cdots+L r^{n}=0
$$

In fact, the general solution depends of the factorization of the polynomial [3] and of the nature of its roots - reals or complex; simple or multiple-, and indirectly his result depends esscntially of the Fundamental Theorem ${ }^{56}$.

55Euler, L. [22].

${ }^{56}$ Each root $r_{j}$ of the polinomial equation [3] furnishes a partial solution into the sum [2] in accordance with the nature of each root $r, j=1, \ldots, n$ :

- if $r_{j}$ is a real simple root of [3], then it furnishes into the sum [2] the sumand

$$
x_{j}=D_{j} e^{r_{j} a_{i}}
$$

- if $r_{j}$ is a multiple real root of inultiplicity $k$, the $k$ equal roots $r_{j}$ furrish into the sum $\{2\}$ the sumand

$$
z_{j, k}=e^{r j}:\left[D_{0}+D_{1} x+\cdots+D_{k-1} x^{k-1}\right]
$$

- if $r_{j}=\alpha_{j}+i \beta_{j}$ is a simple complex root of [3], then it and its conjugate $\overline{r_{j}}=\alpha_{j}-i \beta_{j}$ furnish into the sum [2] the sumand

$$
z_{j}^{*}=e^{\alpha_{j} x}\left[D_{1}^{*} \cos \beta_{j} x+D_{2}^{*} \sin \beta_{j} x\right]
$$

and finally,

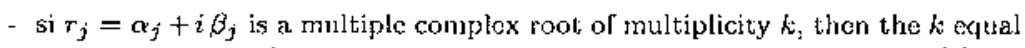
roots $r_{j}=\alpha_{j}+i \beta_{j}$ and their $k$ conjugate roots furnish into the sum [2] the 
The Fundamen'tal theOREM OF aLGEBRA BeFore C.F. Gauss 897

But, as we have already said, the first attempt of demonstration of the Fundamental Theorem of Algebra is debt to d'Alembert ${ }^{57}$.

\subsection{The d'Alembert's attempt.}

Really d'Alembert proves the existence of the root of $P(x)$ in two steps $^{58}$ :

1. There is the minimum $x_{0}$ of the module $|P(x)|_{\text {; }}$

2. The d'Alembert's lemma: if $P\left(x_{0}\right) \neq 0$, then any neighborhood of

sumand

$$
z_{j, k}^{*}=\sum_{\ell=0}^{k-1} e^{\alpha_{i} x} x^{\ell}\left[D_{1}^{* \ell} \cos \beta_{j} x+D_{2}^{* \ell} \sin \beta_{j} x\right]
$$

Somewhat later [Euler, l. $[\mathbf{2 4}$ !] he trcated the nonhomogeneous nth-order linear differential equation

$$
X(x)=A y+B \frac{d y}{d x}+C \frac{d^{2} y}{d^{2} x}
$$

${ }^{57}$ D'Alembert remembers the Jolann Bernoulli's text and then he says: "Nobody, what I know, have went more far [in the question of the decotrposition of polynomials], if we exclude mister Euler, which in the tone VII of Miscellapea Berolinensia declares that he has demostrated the proposition in the general case. But I seem me that Euler never has published yet on this theorem [d'Alembert, J. le Rond [2, 183]1.

${ }^{58}$ See d'Alembert, J. le Tond [2] and Petrova, S. S. [62]. In the d'Alembert's words:

In order to reducc in genemal a differential rational function to the quadrature of the hyperbola or to that of the circle, it is necessary, acrording to the method of M. Bermontli [Mers. Acad. Paris, 1702], to show that every rational polynomint, without a divisor composed of a variable $x$ and of constants, can always be divided, when it is of even degree, into trinomial factors $x x+f x+g, x x+h x+i$, eft , of whach all coeflcients $f, g, h, i, \ldots$ are real. It is clear that this difficulty affects onty the polynomial that cannot be divided by any binomial $x+a, x+b$, etc., becartse we can always by divison reduce to zero all the real binomials, if two are arty, and it can easily be seen that the products of there binonials will give real factors $x: x+f x+g$ [see Struit, D. J. [77, 89, foolibote 1$]$. 
$x_{0}$ contains a point $x_{1}$ such that $\left|P\left(x_{1}\right)\right|<\left|P\left(x_{0}\right)\right|^{50}$.

Then, if 1 and 2 are true and $x_{0}$ is the point in which $|P(x)|$ atteints the minimum, then $\left|P\left(x_{0}\right)\right|=0$. T'his is the sketch of the d'Alembert's proof $^{60}$.

The second step is, for d'Alembert, the more important ${ }^{61}$ and the proof offered by d'Alemberi depends essentially on the Newton's method

${ }^{59} D^{\prime}$ Alembert accepis without demonstration the step 1 and the Newton's method. A simple elementary proof of d'Alembert lemma was given by Argand in 1806. This mathematician was one of the co-discoverers of the geometric reprcsentation of complex numbers. He represents the complex numbers as a vectors into the plan. Then

$$
P(x)=a_{n} x^{n}+a_{n-1} x^{n-1}+\cdots+a_{1} x+a_{0}
$$

is a vector $O A_{n-1}$. The demonstration consists to sec that it is possible to choose $x$ such that the point $A_{n+1}$ coincides with $O$. By seeing this, he cxplains

$$
P\left(x_{0}+\Delta x\right)=P\left(x_{0}\right)+A \Delta x+\text { terms in }(\Delta x)^{2}:(\Delta x)^{3}, \cdots=P\left(x_{0}\right)+A \Delta x+\epsilon
$$

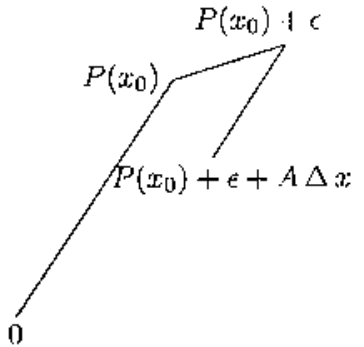

Figure 4

where $A$ is constant and $|\hat{\epsilon}|$ is small compired to $|\Delta x|$ when $|\Delta x|$ is small. Then, choosing the adequate direction of vector $\Delta x$, it is possible obtain that $A \Delta x$ was opposite in direction to $P\left(x_{0}\right)$. Thorı

$$
\left|P\left(x_{0}+\Delta x\right)\right|<\left|P\left(x_{0}\right)\right|
$$

[See Dörrie, H. [21, 108-112], or Stillwell, J. [76, 197-200].]

${ }^{60}$ By secing a complete proof of this kind, see, for example, Aleksandrov et alii [1]; Dörrie, H. [21, 108-112], or Rey Pastor, J. et alii [69, 239-241].

${ }^{61}$ The first step was naturally accepted in the eightecnth century. The rigorous demonstration can be seen into Cauchy, $\mathrm{A}$. [1821], Ch. X: "For every polynomial

$$
P(x)=a_{n} x^{r k}+a_{\tau k-1} x^{n-1}+\cdots+a_{1} x+a_{0} \in \mathbb{C}[x]
$$

there is a $x_{0} \in \mathbb{C}$ such that $\left|P\left(x_{0}\right)\right|=\inf |P\langle\mathbb{C}\rangle|$. 
of polygon ${ }^{62}$. Applying this, d'Alembert obtains

$$
x-x_{0}=\sum_{k \geq 0} c_{k} \cdot\left|y-y_{0}\right|^{q_{k}}
$$

The equation (*) shows that, if $y$ is a real point very close to $y_{0}$, it is the image of any $x$ which appears into the form $p+q \sqrt{-1}$. The the demonstration of the Theorem is founded if we can prove that $y_{0}=0$ is the intage of any $x$ [which will be naturally real or inaginary].

D'Alembert examines the set of real images $y$ and takes the minimum $y_{0}$ which associate $t:$ is of complex form. But following the development $(*)$, all real number $y$ very close to $y_{0}$ must be also an image of the conplex numbers $x$. Then, if $y_{0} \neq 0$, there is an inage closer to zero than $y_{0}$. Contradiction. This contradiction establishes the Theorem.

It is interesting to note two important facts which werc observed by d'Alcmbert into his work. The first are corollaries I and II and proposition LII ${ }^{64}$ and says: "if a complex number $a+b \sqrt{-1}$ is a root of the polynomial $P(x)$, then $a-b \sqrt{-1}$ is inother rooot of $P(x)$ and then $P(x)$ can always be decomposed into quadratic factors of the kind $x x+m x+n$ ".

The second fact, contained in the demonstration but not mencioned explicitly" 65 , is: "if $P(x)$ is a real polynomial and we substitute $x$ by a complex number $z=z_{1}+i z_{2}$, where $z_{1}, z_{2}$ are real numbers, then we obtain $P(z)=Q_{1}\left(z_{1}\right)-i Q_{2}\left(z_{2}\right)$, where $Q_{1}(x)$ and $Q_{2}(y)$ are real polynomials. "Then $P(z)=0$ iff $Q_{1}(z)=0$ and $Q_{2}(z)=0$ "66.

\subsection{The Euler-Lagrange's attempt.}

The idea of Euler's demonstration ${ }^{67}$ was to decompose every monic polynomial with real coeflicients $P(x)$ of degree $2^{x} \geq 4$ into a product

${ }^{22} \mathrm{Sec} N e w t o n$, I. [59] and Stillwell, J. [76, 125-126]. The sense of this theorem is the following: "Jo cvery pair $\left(x_{0}, y_{0}\right)$ of conplex numbers with $y_{0}-P\left(x_{0}\right)=0$, there corsespond an increasing series $\left\{q_{k}\right\}$ of rational numbers such that

$$
x-x_{0}=\sum_{k \geq 0} c_{k} \cdot\left[y-y_{0}\right]^{19 k}
$$

in a neighborhood of yo". "This theorem was proved rigorously by Pusieux in 1850 .

It is possible to avoid this theorom like wo can sce, for example, in Dörrie, H. [21, $108-112$ ].

63 see d'Alembert, J. le Rond [2, 189].

As Sec d'Alembert. J. le Rond [2, 190-19!].

${ }^{65}$ See d'Alembert; .J. le Rond [2, 186-187].

${ }^{66}$ This fact is essential in the first Gauss' demonstration [sec, for example, Hollingsdale, S. $[41,319-322]]$.

67 Sce Enler, L. [23, and Lingrange, J.-L. [45]. 
$P_{1}(x) \cdot P_{2}(x)$ of two monic polynomials with real coefficients of degree $m=2^{n-1}$.

'Thus, if $P(x)$ is a polynomial of the form

$$
P(x)=x^{2 n}+B x^{2 m-2}+C x^{2 n-3}+\ldots,
$$

the polynomials $P_{1}(x), P_{2}(x)$ now take the form

$$
\begin{aligned}
& x^{m}+u x^{m-1}+\alpha x^{m-2}+\beta x^{m-3}+\cdots \\
& x^{m 2}-u x^{m-1}+\lambda x^{m-2}+\mu x^{m-3}+\cdots
\end{aligned}
$$

Then Euler asserts that $\alpha, \beta, \ldots, \lambda, \mu, \ldots$ are real functions in $B$, $C, \ldots, u$, and that, by elimination of $\alpha, \beta, \ldots, \lambda, \mu, \ldots$, is obtained a monic real polynomial in $u$ of degree $\left(\begin{array}{c}2 m \\ m\end{array}\right)$ whose constant term is negative. Now this polynomial in $u$ has a zero $u$ by the intermediate value theorem as Euler clearly knew ${ }^{68}$. Now we can follow quickly the Euler's steps ${ }^{69}$ :

1. If the equation has a root of the form $x+y \sqrt{-1}$, then there is also another of the form $x-y \sqrt{-1}^{70}$;

2. Every equation of odd degree has a least one root;

3. Every equation of even degree with negative absolute term has at least one posilive and one negative root $^{71}$.

But it is the forth theorem which gives us the key of his idcas:

Every equation of the forth degree, as

$$
x^{4}+A x^{3}+B x^{2}+C x+D=0
$$

can always be decomposed into two real factors in the second degree.

First, setting $x=y-\frac{1}{4} A$, he obtains that every equation of the forth degree can be of the form $x^{4}+M x^{2}+N x+P=0$. If we decompose this equation in two equations of the second degree, we have

$$
\left[x^{2}+u x+\alpha\right] \cdot\left[x^{2}-u x+\beta\right]=0 .
$$

${ }^{68}$ This fact is also employed by Iaplace in his demonstration as we will see next. ${ }^{69}$ See Struik, 1).J. [77, 99-102].

${ }^{70}$ Then the polymomial has a factor of the form $x x+p x+q$.

Euler gives an example of how to decompose an equation of the forth degree into two quadratic factors.

So Fuler gives answer to the former problem posed by Nikolaus Bernoulli and Goldbach [sec footnole 54].

${ }^{71}$ We have there a partial proof of the Bolzaro-Cauchy theorem on Intermediate Value. 
If we compare this product with the proposed equation, we shall find

$$
M=\alpha+\beta-u^{2}, \quad N=[\beta-\alpha] \psi, \quad P=\alpha \beta
$$

from which we derive

$$
u^{6}+2 M u^{4}+\left[M^{2}-4 P\right] u^{2}-N^{2}=0,
$$

"from which the value of $a$ must be found. And since the albsolute term $-N \cdot N$ is essentially negalive, we have hope that this equation has at least two real values" 72 .

Among the corollaries to Theorem 4 there is the statement that the resolution into real factor's is now also proved for the fifth degree, and Scholium II points out that, if the roots of the given fourth-degree cquation are $x_{1}, x_{2}, x_{3}, x_{4}$, then the sixth-degree equation in $u, u$ being the sum of two roots of the given equation, will have the six roots $x_{1}+x_{2}, x_{1}+x_{3}, x_{1}+x_{4}, x_{2}+x_{3}, x_{2}+x_{4}, x_{3}+x_{4}$. Since $x_{1}+x_{2}+x_{3}+x_{4}=0$, we can write for $u$ the values $u_{1}, u_{2}, u_{3},-u_{1},-u_{2},-u_{3}$, and the equation in $u$ becones

$$
\left[u^{2}-u_{1}^{2}\right] \cdot\left[u^{2}-u_{2}^{2}\right] \cdot\left[u^{2}-u_{3}^{2}\right]=0^{73} .
$$

${ }^{72}$ When we take one of thein as $t$, then the values of $\alpha$ and $\beta$ will also be real, secing that

$$
2 \beta-u n+M+\frac{N}{u}, \quad 2 \alpha=u+M-\frac{N}{u} .
$$

${ }^{73}$ Wo can observe that the fourth roots $x_{1}, x_{2}, x_{3}, x_{4}$ of the equation

$$
x^{4}+M x^{2}+N x+P=0
$$

satisfies

[2]

$$
x_{1}+x_{2}+x_{3}+x_{4}=0
$$

Then $u$ can have $\left(\begin{array}{l}4 \\ 2\end{array}\right)=6$ different values. 'I'ten th satisfies an equation of the sixth degree which coefficients are reals

$$
F_{65}(t)=0 .
$$

We bave $u_{1}=x_{1}+x_{2}, u_{2}=x_{1}+x_{3}, u_{3}=x_{1}+x_{4}, u_{4}=x_{2}+x_{3}, u_{5}=x_{2}+x_{4}, u_{6}=$ $x_{3}+x_{4}$ and then

$$
u_{1}=-u_{6}, u_{2}=-t_{5}, t_{3}=-u_{4}
$$

and then the cquation [3] has the form

$$
F_{i}(u)=\left[u^{2}-u_{1}^{2}\right] \cdot\left[u^{2}-u_{2}^{2}\right] \cdot\left[u^{2}-u_{3}^{2} \cdot\right.
$$


Next to, into the theorem 5 , he establishes

Every equation of degree 8 can always be resolved into two real factors of the forth degree ${ }^{74}$.

The problem consists to see that not only $u$, but also the other cofficients $\alpha, \beta, \gamma, \delta, \epsilon, \psi$ are reals, a rcasoning which Lagrange and, more later, Gauss objected.

Lagrange takes this equation but he olserves that when $u$ takes the value 0 into the rational expressions of the other coeficients of $P_{1}(x)$ and $P_{2}(x)$ as fonction of $u$, it is possible obtain undefined coefficinets of the form $\frac{0}{0}$. For avoid this, he takes as unknown (wlyen $a_{n_{2}}=1$ ), $v=2 n+a_{n-1}$ and then observes that the "imaginary roots" of the

His constant term is $-u_{1}^{2} u_{2}^{2} u_{3}^{2}$. The product $u_{1}^{2} u_{2}^{2} u_{3}^{2}$ is real? There is. Fuler does not explain this with detail. He says only that; this product is teal because the fundamental theorem of the theory of symumetric functions

We can reasoning this: Despite this product was not a symmetric fonction of the symbols $x_{1}, x_{2}, x_{3}, x_{4}$, it is unvariable when we do all possible permutations of the roots of the equation [1], under the condition [2], between the roots of the equation [1]. Really this product can be obtained of the following:

$u_{1}^{2} u_{2}^{2} u_{3}^{2}=\frac{1}{4}\left\{\begin{array}{l}\left(x_{1}+x_{2}\right) \cdot\left(x_{1}+x_{3}\right) \cdot\left(x_{1}+x_{4}\right)+\left(x_{1}+x_{2}\right) \cdot\left(x_{2}+x_{3}\right) \cdot\left(x_{2}+x_{1}\right)+ \\ +\left(x_{4}+x_{1}\right) \cdot\left(x_{4}+x_{2}\right) \cdot\left(x_{4}+x_{3}\right)+\left(x_{3} \mid x_{4}\right) \cdot\left(x_{3}+x_{2}\right) \cdot\left(x_{3}+x_{1}\right)\end{array}\right\}$.

Remember that the fandarnental theorem of the theory of symmetric functions says:

Every rational forction of roots of an algebraic equation

$$
\varphi\left(x_{1}, x_{2}, \ldots, x_{\eta_{k}}\right)
$$

which lakes $k$ different values when it makes all possible perrnutations of roots, satisfics an algebraic equtution of degree $h$ whose cocfficiertis are rational fonctions of the coefficients of the given equation.

Then, if $k=1$, the fonction $\varphi(x)$ satisfies a rational expression of the coefficients of the given equation.

Euler uses largely this fundamental theorem, but he only develop, with a sufficient rigour, for the general case of the second degree equations, but. the theorem in his general form was proved firstly by Lagrange in his transcendental paper Reflerions sur ta resolution algebrique des equations [177!]. So it will be neccssary hope the Lagrange's apports by obtaining the general result.

${ }^{74}$ First the term $x^{7}$ is eliminated, so that the two supposed factors can be written $x^{4}-u x^{3}+\alpha x^{2}+\beta x+\gamma$ and $x^{4}+u x^{3}+\delta x^{2}+\epsilon x+\psi$. Since $u$ expresses the sum of four roots of the eight-degrec equation, it can have $\frac{8 \cdot 7 \cdot 6 \cdot 5}{1 \cdot 2 \cdot 3 \cdot 4}=70$ values, and it will satisfy an equation of the form

$$
0=\left[u^{2}-p^{2}\right] \cdot\left[u^{2}-q^{2}\right] \cdot\left[u^{2}-r^{2}\right] \cdot\left[u^{2}-s^{2}\right] \cdots
$$

with 35 factors. The absolute term is nerative, and 1 le reasoning continues as before. 
equation in the unknown $v$ are the expressions

$$
\eta_{\sigma}=\sum_{k=1}^{r} z_{\sigma(k)}-\sum_{k=1}^{r} z_{\sigma(k+r)}
$$

where $\sigma$ rums over the set $S_{n}$ of all permutations of set $\{1,2, \ldots, n\}$. It is casy see that the product of $v_{\sigma}$ is always $\leq 0$. Next he avoids the case in which the product is zero, substituing $v_{\sigma}$ for a useful combination of the coefficients of $P_{1}$ with real coefficients and then using his results contained in a paper of $1770-1771^{75}$ on permutations of an equation, finishes rightly the demonstration ${ }^{76}$.

\subsection{The Laplace's attempt.}

In the year 1795, Pierre Simon Laplace made an attempt to prove the Fundanental Theorem ${ }^{77}$. 'This attempt was completely algebraic, but quite different from the Euler-Lagrange attempt. This mathematician and politician assumes, as his predecessors, that the roots of polynomials "exist" 78 .

Laplace says ${ }^{73}$

Of this it results a demonstration very simple of this general theorem which we have ennounced before and which says that every equation of even degree can be solved into real factors of second degree.

His prove is the following: Let be $x_{1}, x_{2}, \ldots, x_{n}$, where $n=2^{k} q, k \leq$ $1, q \in 2 \mathbb{N}+1$, the roots of the polynomial

$$
P(x)=x^{n}-b_{1} x^{n-1}+b_{2} x^{n-2}+\cdots+(-1)^{n} b_{n} \in \mathbb{R}[x], n \leq 1
$$

\footnotetext{
${ }^{75}$ Lagrange, J.L. [45], [1773]. Tlege papers are the most important works on algebraic equations in the ejghtcenth century. See Dieudornc, J. et alii [20, I, 70].

${ }^{76}$ In 1815 Gauss objectes :... this question has been t.reated ab the only problem was determinate the form of roots and its existence is accepted without demonstration. But this mamner of raisoning is completely illusory and it constituties a veritable petitio principis" [Opera Ommia, III, 105-106]. He gives us a demonstration - his second demonstration- Following the Euler's idcas, but he avoids to epply the imaginary roots because nothing "guarantees it existence". [Sec Diendonté, J. et alii $[20,1,71 \mathrm{j}$; Fanvel, J.-Gray, J. [31, 490-491]; Snith, D. E. [74, 292-306] or Remriert, R. [68, 104-106:

${ }^{77}$ Sce "J,eçons de mathématiques donnés a l'Escole Normale", Ocuvncs completes, 14, 10-111, especially 63-65. For an actiual proof and comentaries, see Remmert, $R$. [1 190b], $120-122$.

${ }^{78}$ This existence is naturally a platonic existence.

${ }^{79}$ Japlace, P.-S. [47, (i:3).
} 
The equation $Q_{t}(x)$ which roots are $x_{i}+x_{j}+t\left(x_{i} x_{j}\right)$, where $t \in \mathbb{R}$ arbitrary and $i<j$, has a degree of the form $2^{k-1} q^{\prime}$, where $q^{\prime} \in 2 \mathbb{N}+1^{80}$. Then Laplace proceeds by induction on $k$ :

- if $k=1$, the new polynomial $Q_{t}(x)$ will have an odd degree and then it will be a least a real root $x_{i}+x_{j}+t\left(x_{i} x_{j}\right)^{81}$.

It is clear that there is infinitely many real values $t$ such that, for a same $x_{i}$ and $x_{j}$,

$$
x_{i}+x_{j}+t\left(x_{i} x_{j}\right) \in \mathbb{R} .
$$

Then there are $t_{1} \neq t_{2}, t_{1}, t_{2} \in \mathbb{R}$, such that $x_{i}+x_{j}+t_{1}\left(x_{i} x_{j}\right), x_{i}+$ $x_{j}+t_{2}\left(x_{i} x_{j}\right) \in \mathbb{R}$. Then the quantities

$$
\left[t_{1}-t_{2}\right]\left(x_{i} x_{j}\right), \quad x_{i} x_{j} \text { and } x_{i}+x_{j}
$$

are all real. So the factor $x^{2}-\left[x_{i}+x_{j}\right] x+x_{i} x_{j}$ will bc a real factor of second degree of $P(x)$;

- if $k>1$, then $P(x)$ will have a real factor of second degree if every equation of degree $2^{k-1} q^{\prime}$ has a factor of second degree, because infinitely many

$$
x_{i}+x_{j}+t\left(x_{i} x_{j}\right), i<j, t \in \mathbb{R}
$$

will be complex numbers [that is: they are of the form $\alpha+$ $i \beta, \alpha, \beta \in \mathbb{R}\}$ and then, following the precedent reasoning, there are two roots $x_{i}, x_{j}$ of $P(x)$ such that $x_{i}+x_{j}, x_{i} \cdot x_{j} \in \mathbb{C}$. Therefore the factor

$$
x^{2}-\left[x_{i}+x_{j}\right] x+x_{i} x_{j} \in \mathbb{C}[x]
$$

and it divides exactly $P(x)$. Then

$$
x^{2}-\left[\overline{x_{i}+x_{j}}\right] x+\overline{x_{i} x_{j}} \in \mathbb{C}[x]
$$

divides also $P(x)$. Thus the following real polynomial of forth degree

$$
\begin{aligned}
& {\left[x^{2}-\left[x_{i}+x_{j}\right] x+x_{i} x_{j}\right]\left[x^{2}-\left[\overline{x_{i}+x_{j}}\right] x+\overline{x_{i}} \overline{x_{j}}\right]=} \\
= & {\left[x^{2}-\operatorname{Re}\left(x_{i}+x_{j}\right) x+\operatorname{Re}\left(x_{i} x_{j}\right)\right]^{2}+\left[\operatorname{Im}\left(x_{i} x_{j}\right)-\operatorname{Im}\left(x_{i}+x_{j}\right)\right]^{2} . }
\end{aligned}
$$

This quantity, "as we have seen" 82 , can be solved in two real factors of second degree ${ }^{83}$.

\footnotetext{
${ }^{80}$ Its degree is exactely $2^{k} q\left[2^{k} q-1\right] / 2=2^{k-1} q^{f}$, where $q^{f} \in 2 \mathbb{N}+1$.

${ }^{81}$ Iaplace applies the following corollary of the Intermediate value Theorem: "Every polynomial of odd degree has at least one real root".

${ }^{82}$ Sec Laplace, P.-S. [47, 60-63].

${ }^{83}$ Laplace considers the case in which the two factors
}

$$
\left[x^{2}-\left[x_{i}+x_{j}\right] x+x_{i} x_{j}\right]_{i}\left[x^{2}-\left[\overline{x_{i}+x_{j}}\right] x+\overline{x_{i} x_{j}}\right]
$$


Then the problem is finished because $P(x)$ has a real factor of second degree iff every real equation of degree $2^{k-1} q^{\prime}, q^{\prime} \in 2 \mathbb{N}+1$ has a simmilar factor, and then [for the same reason] iff every equation of $2^{k-2} q^{\prime \prime}, q^{\prime \prime} \in$ $2 \mathbb{N}+1$ has a simmilar factor and following we establish the proof ${ }^{84}$.

\section{References}

1. Aleksandrov, A. D., Kolmogorov, A. N., Laurentiev, M. A. ET ALl1., "Mathematics: Its content, methods, and meaning," M.I.T. Press, Cambridge, Massachussets, 1963.

2. ALEMBERT, JEAN LE ROND D', Recherches sur le calcul intégral, Actes de l'Academie des Scienes de Paris (1746), 182-224.

3. ARGAND, IEAN ROBERT, "Essais sur une manière de représenter les quantités imaginaires dans les construccions géonnétriques," Paris, 1806. Reprint by Albert Blanchard, Paris, 1971.

4. Bashmakova, IsABelda $G$., Le théorème fondamental de l'algèbre et la construction des corps algébriques, Archives Internationelles d'Histoire des Scienes 13 (1960), 211-222.

5. Bernould, JakoB, "Opera," 2 vols., ed. by G. Cramer, Geneva, 1744. Reprint by Birkhaüser, 1968.

have a common factor. This factor must be necessary a factor of the difference of two polynomials and then it must be

$$
\operatorname{Im}\left(x_{i}+x_{j}\right) x+\operatorname{Im}\left(x_{i} x_{j}\right)
$$

If we divide $P(x)$ by this polynomial of first degree, we will have a polynomial with odd degrce and then it will have a real root $r$. The product

$$
\left[\operatorname{Im}\left(x_{i}+x_{j}\right) x+\ln \left(x_{i} x_{j}\right)\right] \cdot[x-r]
$$

constitutes the factor of second degree found.

${ }^{84}$ This proof has a mistake, like we can see in Remmert, $\mathrm{R} .|68,122|$. It is nccessary to see that the polynomial

$$
Q_{t}(x)=\prod_{1 \leq 2<j \leq n}\left\{x-\left(x_{i}+x_{j}\right)+t\left(x_{i} x_{j}\right)\right] \in \mathbf{R}[x]
$$

[that is: all cocficients are reals].

This fact is an easy consequence of the main theorem on synmetric functions which was proved by Newton in 1673 . This theorem says that the coeflicierts of $Q_{t}(x)$ are real because "they are real polynomials in the elcmentary symmetric functions of $x_{1}, x_{2}, \ldots, x_{n} "$ : thitt: is, in the real numbers $b_{1}, \ldots, b_{n}$. 
6. Bernoulti, JoHaNi, Solution d'un problème concernant le calcul integral, avec quelques abregés par rapport à ce calcul, Mémoires de l'Academie Royales des Sciences, Paris (1702), Acta Eroditorum, January 1703, in "Opera Omnia" II, pp. 393 400. Partial English translation in Fauvel, J.-Gray, I., 1987, pp. 436-439.

7. Bernoulu, Johan, Angulorum arcummque sectio indefinita, Acta Eroditorum 31 (1712), 274-277, in "Opera Omnia" I, pp. 511-514.

8. Bernollil, Johann, "Opera Omnia," 4 vols., ed. by G. Cramer, Lausanne and Geneva, 1742. Reprint by Olms Vcrlag. Hildesheim, New York, 1968.

9. Bombelli, RAFAEL, "L'Algebra;" Bologna; 1572. Reprint by Bertolłoti, Feltrinelli Editore, Milano, 1966.

10. Bos, H. J. M., On the representation of curves in Descartes' Géométrie, Archive for History of Exact Sciences 24 (1981), 295-338.

11. BOYER, CARL. B., "A History of Mathematics." John Wiley \& Sons, New York, 1968.

12. Burton, David M., "The History of Malhematics. An Introduction," Allyn and Bacon, Newton, Massachusetts, 1985.

13. CAjori, Florian, Historical notes on the graphic representation of imaginaries before the time of Wessel, Annerican Mathematical Montly 19 (1912), 167-171.

14. CAJORI, FloRian, History of the exponcrtial and logarithnic concepts, American Mathematical Montly 20 (1913), 5-14; 35-47; $75-84: 107-117 ; 148-151 ; 173-182 ; 205-210$.

15. CANTOR, Mori'T2, "Vorlesung über Geschichte der Mathematik," 4 vols; vol. I (3rd ed., 1907), vol. II (2nd ed., 1900), vol. III (2nd ed., 1901), vol. IV (1908), Teubner, Leipzig, 1900.

16. Cardano, Gerolamo, "Ars Magna," 1545. English translation in Witmer, R. 'T., 1968.

17. CAUChy, Augus'T-Louis, Sur les racines imaginaires des équations, in "Oeuwres," I, Ser. 2, 1820, pp. 258-263.

18. Cauchy, August-Lovis, "Oeuvres de A. Cauchy," Ser. 1, 13 vols, Gauthier-Villar, Paris, pp. 1882-1901. Ser. 2, 14 vols, Gauthier-Villars, Paris, 1908-1.938.

19. Descartes, René, "La Géonétrie:" Leyden, 1637. English translation in Smith, D.E.-Latham, M., 1925.

20. Dieudonné, Jean ano ali, "Abrégé d'histoire des mathématiques, 1700-1900," 2 vols, Hermann, Paris, 1978. Reprint shortened in one volum, Hermann, Paris, 1989. 
21. Dörrie, Hernaich, "Thiumph der Mathematik," Physica Verlag; Würrzburg, 1958. English translation by David Antin: "100 Great Problem in Elementary Mathematics", Dover, New York, 1965.

22. ELLER, LEONHARD, De intregratione eçuationm differentialium altiorum gradum, Miscellania berolinensia 7 (1743), 193-242, in "Opera Omnia" XXII, ser. 1, pp. 108-149.

23. EuLER, LEONHARd, Recherches sur les racines imaginaires des équations, Histoire de l'Académie Royale des Sciences et Belles Lettres, Anné MDCCXLIX, Berlin 1751, 222-228, in "Opera Omnia" VI, ser. 1, 1749, pp. 78-147.

24. EULER, Llonhard, Methodus aequationes differentialibus, quaecertis tantum casibus integrationem admittunt, Novi Commentaria Academia Scientifuarum Pelrp. 3 (1750), 3-35, pub. 1753 in "Opera Onnie" XXIY, ser. 1, pp. $181-213$.

25. Eular. Leonhard, De formulis differentialibus angularibus, published in the posthmous vol. IV in Euler, L., 179t4, IV.

26. EulEr, LeONHARD, Instilutiones calculi integralis, in "Opero Omnia.," XIX, ser. 1, 1794, pp. 129-140.

27. EULER, LEONHARD, "Conrespondance mathématique et physique de quelques célébres géonètres du $X V / T^{c}$ siècl," 2 vols., edited by $\mathrm{P}$. H. Fiss, Petersbourg; 1843.

28. EULER. LlONHARI, "Lefnhardi Euleri Oprea postuma mathematica et physica," 2 vols., edited by P. H. and N. Fuss, Petersbourg, 1962.

29. Euler, Leonhand, "Oprera Omara," ed. by Soc. Scient. Natur. Helvetica, Teubner, Leipzig and Berlin, 1911-1985, Füssli, Zürich, four series.

30. EWING, JoHN H. (EDrTOR), "Numbers:" Springer-Verlag, New York, 1990. It is an English translation by H. S. L. Orde of Second edition of the German original Zahlen, Springer-Verlag; 1988.

31. FAUVI:, JoHN-GRAY, JEREMY (Entrors): "The History of Mathematics - A reader-" MacMillan, New York, 1987.

32. Fermat, Pierre, Ad locos plamos et solidos isagoge, in "Oeuvres," 1629, pp. 32-103.

33. Fermat, Pierre; "Oeuves," 4 vols., ed. P. Tannery, Gauthiers-Villars, Paris, 1896.

34. Gnuss, Carl Fritsrich, "Werke," 12 vols., ed. by Königliche Gesellschaft für Wissenschaften, Göttingen, Leipzig and Berlin, 1863-1933.

35. GerhArD, C. I. (EDTTOR), "Leibniziens mathematische Scriften," 7 vols, Halle, 1850-1863. Reprint by Olms Vrelag, Hidelsheim, 1962. 
36. Gerhard, C. I. (EDTTOR): "Briefwechsel von G.W. Leibniz mit Mathematikern," Berlin, 1899.

37. Gilain, Christian, Sur lhistoire du théoreme fondamental de l'algèbgre: théorie des équations et calcul integral, Archive for History of Exact Sciences 42 (1991), 91-136.

38. Girard, AlberT, "L'Invention nouvelle de l'Algèbre," Amsterdam, 1629. Partial English translation by Ellen Black in Viète at alii, 1986, pp. 105-198.

39. Harriot, Thomas, "Artis Analytice," Praxis, London, 1631.

40. Hofmann, Joseph E., "Leibniz in Paris, 167\% -1676", Cambridge University Press, Massachusetts, 1972.

41. Hollingsdale, Stuart, "Makers of Mathematics," Penguin Books, London, 1989.

42. Houzet. Christian, D'Alembert et le thèoréne fondamental de l'algèbre, in "Jean d'Alembert, savant et philosophe; portrait à plusienurs voix," Editions des archives contemporaines, Paris, 1989, pp. 351-360.

43. Jones, Phillip S., Complex Numbers: an example of recurring themes in the development of mathematics, I and II, The Mathematical Teacher 47 (1954). 106-114, 257-262.

44. KLINE, MORRIS, "Mathematical thought from ancient to modern times," Oxford University Press, New York, 1972. There is an edition in three volums (paperback), Oxford University Press, New York, 1990.

45. LAGRANGE, JOSEPH LOUIS, Sur la forme des racines imaginaires des équations, Nouveaux Mémoires de l'Acadénie Royale des Sciences et Belles Lettres, Amć MDCCLXXI, Berlin 1774, 222 228, in "Oeuvres complètes", III, 1772, pp. 477-516.

46. LAGRANGe, Joseph Louls, "Oenves complètes," 14 vols, ed. by J. Serret, Gauthier-Villars, Paris, 1867-1892.

47. Laplace, Pierre Simon, Leçons de mathématiques donnés à l'Ecole normale en 1795, in "Oeuvres complètes;" XIV, 1795, pp. $10-177$.

48. LaPlace, Pibrre Simon, "Oeuves complètes," 14 vols, Gauthier-Villars, Paris, 1878-1912.

49. Leibniz, GotTfined Wilhelm, "De Bisectione Laterum," 1675. See Schneider, I., 1968, 224.

50. Leibniz, GotTFried Whihelm, Specimen novum analyseos pro scientia infinity circa summas et quadraturas, Acte Eroditorum, May 1700 in Gerhardt, C.I., 1859, 350-361. French translation by Marc 
THE: FUNDAMIENTAL THFOREM OF ALGEBRA BEFORE C.F. GAUSS 909

Parmentier in Leibniz, G.W., 1989, 387-401.

51. Leibniz, GotTfries Wiluslm, Extrait d'une lettre de Mr. Leibniz a Mr. Varignon, tiré du Journal of Savant de l'anné 1702, in Leibuiz, G.W., 1983.

52. LEIBNIZ, GOT'TFRIED WILHEM, Continuatio Analyseos Quadratorum Rationalinm, Acta Froditortum, January 1703, in Gerlated, C.I., 1850, V, 361-377. French translation by Marc Parmentier in Leibriz, G.W., 1989, 402-422.

53. LEIBNH, GOTTFRHED WILHELM, "Oeuve concernant le calcul infinilésimal," 1983. Translated to French by Jem Peyroux, Blanchard, Paris.

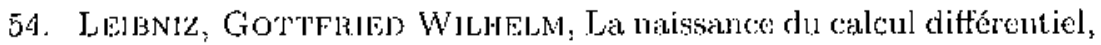
26 articles des Acta Eroditorum, lrotroduction, translation and notes by Marc Parmontier, Vris, Paris (1989).

55. MCCLENON, R. B., A contribution of Leibuiz to the history of complex numbers, American Mathematical Montly 30 (1923), 369-374.

56. Mulhad, Gascon, "Descartes samme," Alcan, Paris, 1921.

57. MOLAS, Cori AND PÉrez, Juli, El naixement dels nombres complexos, Bulletí de la Societat Catalama de Matematiques 5 (1990). $37-66$.

58. NaUx, I., "Whistoite des logathms;" Blanchard, Paris, 1966.

59. NEwTON, ISAAC, De methodis serierum et fluxionum, in "Neutort," I, 1967-1981, III, jp. 32-353.

60. NGwTOx, ISAAC, "Arithmetica Universalis," 1707, Second edition (1728), Cambridge, in "Newton", I., 1967, V, pp. 54-532.

61. Newton, ISAaC, "Mathematical Papers of isanc Nemtort," 8 vols., edited by Whiteside, D.T. Cambridge University Press, Cambridge, 1967-1981.

62. PETrova, S. S., Sur 'Histoire des démonstrations analytiques du thcorème fondanental de l'algèbre, Historia Mathematica 1 (1974), $255-261$.

63. PLA, Josel', La Géométrie de Descartes con un exemple de La Méthode, (calialan), Actas del III Congreso de los Lenguajes Natzwles $y$ los Lenguajes Formales III (1987), 821-863.

64. Pl,A, Joser, Les sèries en Newton, Bulletr de la Societat Catalana do Matenatiquaes 4 (1989), 9-21.

65. Pusslsux, V.-A., Recherches sur les fonctions algébriques, Joumal of Mathematics 15 (1850), 365-480.

66. Rahn, Johann Heinrich. J., "Teutschen Algebra," Zürich, 1659. 
67. Remmert, Reinhold, "Complex Numbers;" in Ewing, J. H., 1990, pp. $55-96$.

68. Remmert, ReINHOLd, "The Fundamental Theorem of Algebra," in Ewing, J. H., 1990, pp. 97-122.

69. Rey Pastor, Julio-Pi Calleja, Pedro-Trejo and César a., "Análisis Matemático," Editorial Kapelusz S.R.I., Buenos Aires, Argentina, 1951.

70. Ro'TH, PETER, "Arithmetica philosophica," Nürnberg, 1600.

71. Sсотт, John F., "The scientific work of Rene Descurtes," Taylor and Francis, London, 1952.

72. Scherden, I., Der Mathematiker Abraham de Moivre (1667-1754), Archive for History of Exact Sciences 5 (1968), 1.77-317.

73. SMITH, DAvid EUGENe, "History of Mathematics;" 2 vols (first volum (1923), second volum (1925)), Constable and Company, Ittd. London, 1925. Reprint by Dover, New York, 1957.

74. Smiti, David Eugene (editor), "A Source Book in Mathematics," 2 vols., McGraw-Hill, New York, 1929. Reprint by Dover. New York, 1959.

75. Smith, David Eugene-Lajham, Marcia, "The Geometry of René Descartes:" Dover, New York, 1954.

76. Stillwell, JOHN C., "Malhematics and its History" SpringerVerlag, New York, 1989.

77. STRuik, Dirk J., "Source Book in Mathematics, 1200-1800", Harvard Universily Press, Cambridge: Massachusetts, 1969.

78. Tartaglia, Niccolò, "Quesiti et Inventione Diverse," Facsimile of 1559 edition, ed. A. Masotti, Ateneo di Brescia, Brescia, 1546. Partial English translation in Fauvel, J.-Grey, J., 1987, pp. 254-256.

79. Troprkf, JoHAnNEs, "Geschichte der Elementar-Mathematik in systematischer Darstellung," 7 vols., third cdition of vol. III, 1937.

80. Vera, Francisco, "20 Matemáticos Célebres," Los libros del Mirasol, Argentina, 1961.

81. VIÈ'TE, FRANÇOIS, De equatione recognitione et ernendatione, in "Opera Mathematica," 1646, pp. 82-162. There is also an English translation in Witmer, R.1., 1983, pp. 159-310.

82. Vière, Francois, "Opera Mathematica" published by Franciscus van Schooten with cornmentaries, Leiden, 1646. Reprint by Georg Olms Verlag, Hildesheim, New York, 1970.

83. VIETE, F. ET ALl1, "Three Theatises by Viète, Giratd and deBeaune," Golden Hint Press, Annapolis, Maryland, 1986. 
84. Waprden, Baklel Leenert VAn DFR, "Modetr Algebra," Froderick Ungar, Now York, 1919.

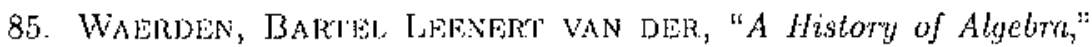
Springer-Verlagg: New York, 1985.

86. Whisus, JoIn, "Algebru," Isondon, 1673. In "Opera Ommia", II, Pp. $1-482$.

87. WALLJS, JoHN, "Theotise of Algebra," 1685. English trauslation by Wallis of the "Algebra", London.

88. Wablis, JOHN, "Opera Ommia," 3 vols, Georg Olins Verlag, Hidelshein, New York, 1972.

89. Wessel, CAsPAK, Om diretioneus analytiske Betegning el Forsög anwendt foremelig iil plane of sphaneriske Polygoners Oplössing: Danske Selsk. Skr. N. Sarml. 5 (1797). Partial English translation in Suith, D. E., 1929, I, 55-66.

90. WiTMlir, R. 'Г., "The great art" Carbridge, Massachusetts, 1968.

91. Wirmer, R. T., "The analytic aml," Kate State University Press, Kent, Ohio, 1983.

Departament de Lógicát, Història i Filosofiez de la Ciènciat

Universitat do Barcolona

Grau Via de los Corts Catalanes 585

08007 Barcelona

SPA!N

Rebut el 13 de Gener de 1992 